\title{
Enhanced Excitability of Thalamic Sensory Neurons and Slow-Wave EEG Pattern after Stimuli That Induce Spinal Long-Term Potentiation
}

\author{
Raul Sanoja, Niwat Taepavarapruk, Elke Benda, Ramakrishna Tadavarty, and Peter J. Soja \\ Faculty of Pharmaceutical Sciences, The University of British Columbia, Vancouver, British Columbia, V6T 1Z3 Canada
}

\begin{abstract}
Spinal nociceptive neurons are well known to undergo a process of long-term potentiation (LTP) following conditioning by high-frequency sciatic nerve stimulation (HFS) at intensities recruiting C-fibers. However, little if any information exists as to whether such HFS conditioning that produces spinal LTP affects sensory transmission at supraspinal levels. The present study explored this possibility. Conventional extracellular recording methods were used to examine the consequences of HFS versus sham HFS conditioning on individual wide-dynamic range thalamic neurons located in the ventro-postero-lateral (VPL) nucleus in isoflurane-anesthetized rats. Following HFS, the ongoing firing rate and stimulus-evoked (brush, pinch, sciatic nerve) responses were markedly enhanced as were responses to juxtacellular, microiontophoretic applications of glutamate. These HFS-induced enhancements lasted throughout the recording period. Sham stimuli had no effect on VPL neuron excitability. Cortical electroencephalographic (EEG) wave activities were also measured around HFS in conjunction with VPL neuron recordings. The cortical EEG pattern under baseline conditions consisted of recurring short duration bursts of high-amplitude slow waves followed by longer periods of flat EEG. Following HFS, the EEG shifted to a continuous large-amplitude, slow-wave pattern within the $0.5-8.0 \mathrm{~Hz}$ bandwidth lasting throughout the recording period. Sham HFS did not alter EEG activity. Sciatic nerve conditioning at A- $\delta$ fiber strength, known to reverse spinal LTP, did not alter enhanced neuronal excitability or the EEG slow-wave pattern induced by HFS. These data support the concept that HFS conditioning of the sciatic nerve, which leads to spinal LTP, is associated with distinct, long-lasting changes in the excitability of neurons comprising thalamocortical networks.
\end{abstract}

\section{Introduction}

Substantial evidence exists that the magnitude of C-fiber-evoked field potentials is enhanced over a period of several hours immediately following brief, high-intensity phasic tetanic stimulation or high-frequency stimulation (HFS) of the sciatic nerve (Randić et al., 1993; Liu and Sandkühler, 1995, 1997; Sandkühler, 2007). This phenomenon has been referred to as spinal long-term potentiation (LTP). Spinal LTP is currently regarded as a cellular model of hyperalgesia induced by intense stimulation (Sandkühler, 2007). Conditioning by similar HFS stimuli also enhances action potential discharges in spinal dorsal horn neurons (Svendsen et al., 2000; Gjerstad et al., 2001).

Spinal LTP was initially reported to be suppressed by tonic descending inhibition (Liu and Sandkühler, 1998; Liu et al., 1998). The HFS-induced enhanced discharge of spinal dorsal

\footnotetext{
Received May 17, 2013; revised July 24, 2013; accepted Aug. 13, 2013.

Author contributions: P.J.S. designed research; R.S., N.T., E.B., and P.J.S. performed research; P.J.S. contributed unpublished reagents/analytic tools; R.S., E.B., R.T., and P.J.S. analyzed data; R.S., N.T., E.B., R.T., and P.J.S. wrote the paper.

This work is funded by grants (MOP-89909, TGS-109219) from the Canadian Institutes of Health Research to P.J.S. The authors declare no competing financial interests.

Correspondence should be addressed to Dr. Peter J. Soja, Faculty of Pharmaceutical Sciences, The University of British Columbia, 2405 Wesbrook Mall, Vancouver, BC, V6T 123 Canada. E-mail: drpsoja@mail.ubc.ca.

R. Sanoja's present address: Merck \& Co., Inc., 770 Sumneytown Pike, West Point, PA 19486.

N. Taepavarapruk's present address: Physiology Department, Faculty of Medical Science, Naresuan University, Phitsanulok 65000 Thailand.

DOI:10.1523/JNEUROSCI.2110-13.2013

Copyright $\odot 2013$ the authors $\quad 0270-6474 / 13 / 3315109-11 \$ 15.00 / 0$
}

horn neurons is more robust when "descending inhibition" is released following transection or interruption of spinal conduction a few segments rostral to the site of recording (Gjerstad et al., 2001). In spinally intact anesthetized animals, HFS stimuli might be expected, via ascending projection pathways, e.g., the spinothalamic tract, and/or indirectly from the cortex via other ascending spinocortical pathways (Manjarrez et al., 2002a, b), to influence higher brain centers including the thalamus and/or cortex. Surprisingly, however, this critical issue has never been addressed. Another critical feature of spinal LTP is its apparent reversibility. Indeed, it has been claimed that tetanic sciatic nerve stimuli, at intensities that recruit $\mathrm{A} \delta$-fibers, suppress $\mathrm{C}$-fiber-evoked potentials in the spinal cord leading to long-term depression (LTD). The same HFS stimuli recruiting $\mathrm{A} \delta$-fibers depotentiates established LTP in the spinal cord (Liu et al., 1998). Accordingly, one might also reason that phasic depotentiation stimuli that reverse spinal LTP might likewise suppress thalamocortical modifications should it manifest following HFS.

Here, we addressed these key issues in spinal intact anesthetized rats directly by quantifying ongoing spike rate and pattern activities of wide-dynamic range (WDR) neurons located in the ventro-postero-lateral nucleus (VPL) as well as their response magnitude to natural, peripheral nerve-evoked, and glutamateevoked forms of excitation before and after HFS conditioning of the sciatic nerve. We also investigated the reversibility of HFSinduced changes in VPL neuronal excitability following equivalent stimuli that depotentiate spinal LTP. 
Given that the majority of thalamic VPL neurons are relay neurons that project to the somatosensory cortex (Saporta and Kruger, 1977; Herkenham, 1980; Yeterian and Pandya, 1985, 1994; Jensen and Killackey, 1987; Jones, 2007; Liao and Yen, 2008), we explored for the first time the consequences of the same HFS stimuli and depotentiating stimuli on cortical electroencephalographic (EEG) activity in conjunction with thalamic VPL neuron excitability.

Our findings provide quintessential evidence that thalamocortical neurons may undergo marked dynamic changes during isoflurane anesthesia along with lumbar neurons following a brief period of synchronous, high-intensity/frequency stimuli applied to the sciatic nerve.

\section{Materials and Methods}

All experimental procedures described herein were approved by the University of British Columbia Committee on Animal Care. Adult male Sprague Dawley rats (270-300 g), were prepared for single neuron recording from the VPL thalamic nucleus under continuous isoflurane anesthesia. Before anesthesia and electrophysiological recording experiments, the animals were housed in standardized conditions with $12 \mathrm{~h}$ light/dark cycles and ambient temperature $\left(21^{\circ} \mathrm{C}\right)$. The animals were fed on standard laboratory rodent chow, with access to water ad libitum.

\section{Surgical procedures}

Anesthesia was induced by placing the rat in an anesthetizing box (\# 500108; Harvard Apparatus) that was supplied with a continuous stream of isoflurane $(4 \%)$ in oxygen $(3 \mathrm{~L} / \mathrm{min})$. Once the animal lost its righting reflex, it was removed from the chamber and the anesthetic mixture thereafter was delivered through a custom-made nose cone until tracheal intubation. Following a tracheostomy, the trachea was intubated, the isoflurane and oxygen levels were then lowered to $2.5 \%$ and $1 \mathrm{~L} / \mathrm{min}$, respectively. The isoflurane levels were controlled using a calibrated isoflurane solution vaporizer (Model 100F; Ohio Medical Products, Airco). A surgical plane of anesthesia was confirmed by the absence of blink and toe-pinch reflexes. The rectal body temperature was constantly monitored and maintained at $37.2 \pm$ $0.1^{\circ} \mathrm{C}$ using a feedback-controlled heating blanket. Heart rate, blood oxygen levels, and end tidal $\mathrm{CO}_{2}$ were continuously monitored with a pulse oximeter/capnograph (SurgiVet; Smiths Medical) and were kept within normal physiological limits at all times.

Cranial trephination and sciatic nerve surgical procedures. The rat's head was secured in a stereotaxic frame. A midline incision was made in the scalp to expose the calvarium. A trephination was made in the right parietal bone, contralateral to the site of the peripheral nerve surgery for introducing a microelectrode into the VPL nucleus of the thalamus [from bregma: anterior-posterior $(\mathrm{AP})=-3.6 \mathrm{~mm}$, mediolateral $(\mathrm{ML})=+3.6 \mathrm{~mm}$, dorsoventral $(\mathrm{DV})=5-7 \mathrm{~mm})$. Recordings were made with tungsten microelectrodes with a certified impedance of $2 \mathrm{M} \Omega$ measured at $1 \mathrm{kHz}$ (A-M Systems). In addition, bilateral trephinations were made in the parietal bone to fix screws (S1) for recording the parietal-cortical EEG (from bregma: $\mathrm{AP}=-1.0 \mathrm{~mm}, \mathrm{ML}= \pm 3.0 \mathrm{~mm}$ ). A ground screw electrode was threaded into the left frontal bone. These screw electrodes were used to monitor the surgical plane of anesthesia, before and during neuromuscular blockade and changes in cortical excitability before and after induction of spinal LTP (Fig. 1). Recording amplifier filters were set between 0.5 (high-pass) and 35 (low-pass) $\mathrm{Hz}$ (half-amplitude attenuation). A $60 \mathrm{~Hz}$ notch filter was also used.

The left sciatic nerve was exposed and bathed in a pool of warm mineral oil. The nerve was carefully draped on a bipolar hook electrode to synaptically activate recorded VPL neurons (Fig. 1).

\section{Electrophysiological procedures}

Spike data acquisition and amplification procedures. The extracellular spike activity of an individual thalamic VPL neuron was recorded using a tungsten microelectrode. In microiontophoretic experiments (see below) a multibarrel electrode (Fig. 1) was gradually lowered into the right thalamic VPL nucleus matter using a Kopf hydraulic microdrive (Model 650; David Kopf Instruments). Spike activity was amplified $(\times 1000)$ and filtered (bandpass: 300-5000 Hz) using an AC-coupled differential amplifier (Model 1800; A-M Systems; Fig. 1, Microelectrode Amplifier). The amplified signal was then routed to an oscilloscope (Model D11; Tektronix) and a spike processor (Model D130; Digitimer; Fig. 1, WD), which was manually set to detect only the VPL neuron action potential waveforms. The amplified and filtered VPL neuron spike activity as well as the EEG signals were recorded and digitized "on-line" into separate waveform channels using a Pentium computer equipped with spike acquisition and analysis software (Spike 2, version 6.16; Cambridge Electronics Design, CED) and hardware (Power1401 plus; “CED-1401"). The sampling rates for the VPL neuron spike wave data and EEG were 16.6 and $2000 \mathrm{~Hz}$, respectively. A spike template-sorting subroutine in Spike 2 was used to verify that the sampled spike data were recorded from the same VPL neuron across the recording period. Tolerance criteria included ensuring that accepted spikes did not deviate by $10 \%$ in peak-to-peak spike amplitude. This procedure allowed us to clearly discern between two different neuronal recordings when simultaneously recorded units were recorded (Soja et al., 1996; Taepavarapruk et al., 2002). Tolerance criteria were set to ensure that accepted spikes did not deviate by $10 \%$ in peak-to-peak spike amplitude. Data files of each VPL neuron, in conjunction with left and right EEG recordings (S1), were stored on a data server for subsequent off-line analysis using specialized subroutine scripts. Nonoverlapping $60 \mathrm{~s}$ epochs of EEG activity were analyzed for all control and test conditions using a fast Fourier transform (FFT; 512 point, Spike 2 script, SUDSA version 2.2) and plotting frequency/power plots across standard EEG bandwidths, i.e., $\delta(0-4 \mathrm{~Hz}), \theta(4-8 \mathrm{~Hz}), \alpha$ $(8-12 \mathrm{~Hz})$, and $\beta(12-30 \mathrm{~Hz})$.

Characterization of thalamic VPL neurons. Neurons encountered in the VPL nucleus of the thalamus were characterized on the basis of their response to natural forms of stimuli applied to hindlimb peripheral receptive fields and their response to a single high-intensity electrical pulse stimulus $(0.5 \mathrm{~ms}, 10 \mathrm{~V})$ applied to the sciatic nerve. Neurons excited phasically by light brush stimuli and weak mechanical dimpling of the hindlimb, as well as in a sustained fashion to a pinching of the skin, toe pads using hand-held rat-tooth forceps and finally with a burst of action potentials to a single high-intensity sciatic nerve stimulus, were characterized as WDR neurons (Sherman et al., 1997; Gerke et al., 2003; Hains et al., 2006; Iwata et al., 2011). 
Spontaneous spike activity. The ongoing spontaneous spike activity for each thalamic VPL neuron was assessed by quantifying firing rate (Soja et al., 1996; Taepavarapruk et al., 2002). The average spike firing rate (spikes/s) for each VPL neuron was calculated from 1 min epochs of the spike waveform under control and test conditions. Thalamic neurons are known to fire in spike relay and burst modes (Steriade, 2003). To determine whether alterations in spike pattern occurred following HFS, we used a specialized Spike 2 script subroutine (Burst6.s2s).

Microiontorphoresis procedures. In several experiments, the responsiveness of WDR VPL neurons to pulsatile, juxtacellular microiontophoretic ejections of excitatory amino acid glutamate (GLU) was examined around HFS. The central carbon fiber-containing recording barrel was surrounded by four barrels (Carbostar-4, E1061; Kation Scientific) filled with GLU $(0.5 \mathrm{M})$ and sodium chloride $(\mathrm{NaCl} ; 4 \mathrm{M})$. All drugs used for microiontophoresis were dissolved in distilled water and were obtained from Sigma. Glutamate was ejected in a pulsatile manner using negative currents that produced submaximal responses ( $15 \mathrm{~s}$ ejection epochs, $20 \mathrm{~s}$ intervals, -60 to $-80 \mathrm{nA})$. Positive retention currents $(10 \mathrm{nA})$ were continuously applied to each drug barrel to minimize spontaneous leakage. Automatic current neutralization procedures were performed using a drug barrel containing $4 \mathrm{~m} \mathrm{NaCl}$ during drug microiontophoresis (Soja et al., 2001; Taepavarapruk et al., 2002).

\section{Experimental procedures}

HFS induction. Once a WDR neuron was characterized, the following experimental protocol was applied. After 5 min or more of background activity recording, three identical batteries of stimuli were presented before induction of thalamic LTP. Each battery consisted of a mechanical brushing stimulus of $10 \mathrm{~s}$ duration, followed by a mechanical pinch stimulus of $2 \mathrm{~s}$ duration, and finally with a high-intensity single shock stimulus of $10 \mathrm{~V}$ in $0.5 \mathrm{~ms}$ to the sciatic nerve. The time interval between stimulus batteries was 4-6 min. If after three stimulus batteries series responses of the WDR neuron under study were deemed to be consistent, the animal was then paralyzed with pancuronium bromide $(0.2 \mathrm{mg} / \mathrm{kg}$ initial dose, $0.1 \mathrm{mg} / \mathrm{kg} / \mathrm{h}$ maintenance dose; Sandoz) and artificially ventilated. Paralysis was confirmed by absence of movement to electrical stimulation. No changes in neuron firing properties were detected before versus during, or after pancuronium paralysis. Once muscular paralysis was confirmed, the isoflurane concentration was increased to $2 \%$ for 2 min during which HFS ( $45 \mathrm{~V}, 0.5 \mathrm{~ms}, 100 \mathrm{~Hz}$ ), was delivered over a total time period of $1 \mathrm{~min}$ (Liu and Sandkühler, 1995). In sham experiments, stimulation was performed at $0 \mathrm{~V}$ keeping identical all other parameters. Isoflurane level was then reset to $1.25-1.5 \%$. Then, the same battery of stimuli was applied at regular intervals throughout the remainder of the experiment. Previous studies have reported that raising surgical levels of anesthesia by the volatile anesthetic isoflurane from 1 to $2 \%$ and back to $1 \%$ failed to prevent synaptic LTP in nociceptive pathways (Benrath et al., 2004). Neuromuscular blockade provided by pancuronium lasted $\sim 45 \mathrm{~min}$ after the conditioning stimulation paradigm.

Depotentiation procedure. In several experiments after HFS-induced alterations in thalamocortical networks dynamics occurred, attempts to reverse such changes were performed where depotentiation stimuli were delivered to the sciatic nerve (Liu et al., 1998). Briefly, prolonged low-intensity trains $(0.1 \mathrm{~ms}, 10 \mathrm{~V}$, $100 \mathrm{~Hz}, 1 \mathrm{~s}$ train duration at $10 \mathrm{~s}$ train intervals for $15 \mathrm{~min}$ ) were applied to the sciatic nerve. Regular stimulus batteries were then presented and the VPL neurons' responses recorded and quantified (see above).

\section{Statistical analysis procedures}

The statistical analysis was performed using GraphPad (Prism, version 5.0) and SigmaStat (version 3.5; Systat Software). In this study, the principal objective was to detect significant differences in each thalamic VPL neuron parameter or EEG bandwidth power values following HFS or sham stimuli at each time point against the respective pre-HFS or pre-sham baseline values rather than among the time points. Group mean values of each electrophysiological parameter (ongoing spike activity, brush, pinch-evoked, or sciatic nerve stimulus-evoked activities or EEG bandwidth power) measured before HFS or sham served as the corresponding baseline (control). Group mean values at each time point (i.e., 5, 15, 30, 45, and 60, 90, 120, $180 \mathrm{~min}$ ) following HFS (test) or sham (test) were compared against the respective control values using a one-way repeated-measures (Friedman test). The significant differences were further analyzed with a Dunn's multiple-comparison test. The Mann-Whitney sum test was used to assess the difference between nonnormally distributed population means. In all cases, $p<0.05$ was considered statistically significant. Individual $p$ values are provided for each appropriate test in text. Asterisks in figures denote statistically significant differences from corresponding controls $(p<0.05)$. All the values in results are expressed as means \pm SEM unless otherwise noted, such as mean \pm SD.

\section{Histological procedures}

At the end of each experiment, while the animal was under isoflurane anesthesia, the location of the tip of the recording electrode in situ was marked by applying current $(20 \mu \mathrm{A}, \mathrm{DC}, 10 \mathrm{~s})$. Then, the isoflurane anesthesia was gradually withdrawn and replaced by a continuous intravenous infusion of pentobarbital $(10 \mathrm{mg} / \mathrm{kg} / \mathrm{h})$ during which the brain was carefully removed. Each brain was then blocked, placed in cold $4 \%$ paraformaldehyde, and postfixed for $24 \mathrm{~h}$. Coronal sections $(40-50 \mu \mathrm{m})$ were performed using a microtome (Vibratome 1000 Classic). Sections were slide mounted, counterstained with hematoxylin QS (Vector Laboratories), and permanently fixed for analysis. Selected brain sections of the thalamus were imaged using a digital scanner system (ScanScopeCS; Aperio Technologies) at $\times 40$ magnification. The images were digitally processed with ImageScope (Aperio Technologies) and Adobe Photoshop version 7.0 (Adobe Systems). The anatomical sites of recordings and microinjections obtained from all of the rats were plotted on a standard coronal section of the brain (Paxinos and Watson, 2007).

\section{Results}

\section{Response characteristics of VPL neurons to natural and} sciatic nerve stimuli: effect of HFS

A total of 64 neurons was examined in this study. Of these, 22 rats were used to assess the effects of sciatic nerve conditioning on $40 \mathrm{VPL}$ WDR neurons. Of these 40 neurons, 30 were used as their own controls and then to assess HFS stimuli. Additionally, 10 neurons were used as their own controls before and after sham stimuli were applied to the sciatic nerve. Multiple neurons were recorded in most experiments. Based on rigid spike template criteria (see Materials and Methods), 26 neurons were recorded simultaneously from 11 experiments in the HFS group and 6 neurons were recorded simultaneously from 3 experiments in the sham group. To assess the effects of depotentiation stimuli, 14 WDR neurons were recorded from seven rats. Finally, 10 VPL neurons in six rats were examined in microiontophoretic experiments.

Under baseline conditions of 1.5\% isoflurane, WDR VPL neurons displayed a rapidly adapting short-duration burst of action potentials during presentation of innocuous brush stimuli applied to receptive fields incorporating the plantar surface and up to the lower thigh (Fig. 2A). Pinch stimuli applied to the same receptive field evoked a more intense burst of action potentials that was sustained during the application of the stimulus. Single shock C-fiber strength stimuli applied to the sciatic nerve (Benrath et al., 2004; Ikeda et al., 2006) evoked a short burst of action potentials (Fig. 2A).

The average response profile of all neurons recorded to each of these stimuli was quantified and served as a baseline for comparison with evoked responses following sham or HFS conditioning stimuli applied to the sciatic nerve. The response magnitude of VPL neurons to brush, pinch, and sciatic nerve stimuli was essentially doubled at 5 , 15 , and 30 min following the delivery of HFS stimuli to the sciatic nerve. Figure 2 illustrates the marked enhancement in the number of action potentials of a thalamic neuron following HFS. A prominent feature noted was the sustained after-discharge of spike activity following the cessation of brush versus pinch-evoked responses, such that, following HFS, both brush and pinch-evoked responses were essentially indistinguishable from each other (Fig. 2A,B). The short burst of action potentials that normally occur following single shock 
A

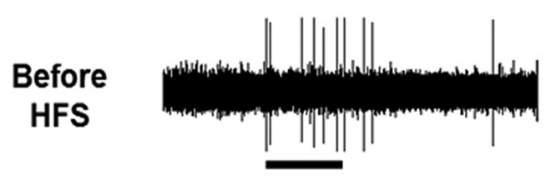

B

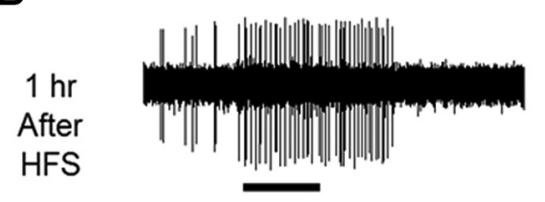

C

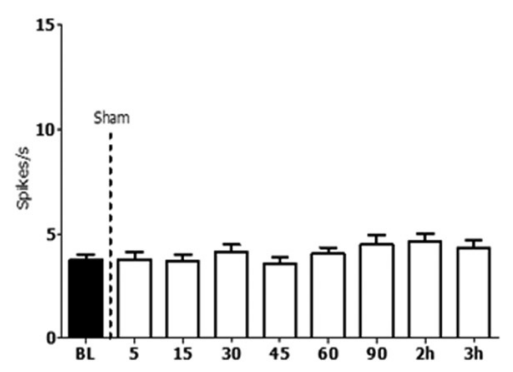

D

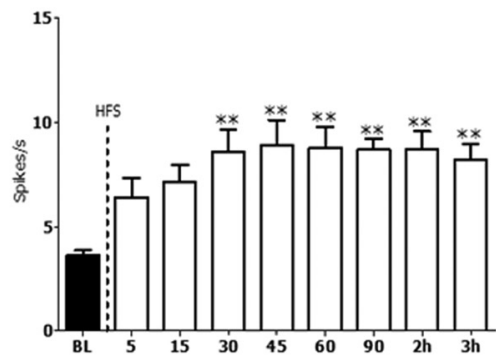

Noxious - Pinch
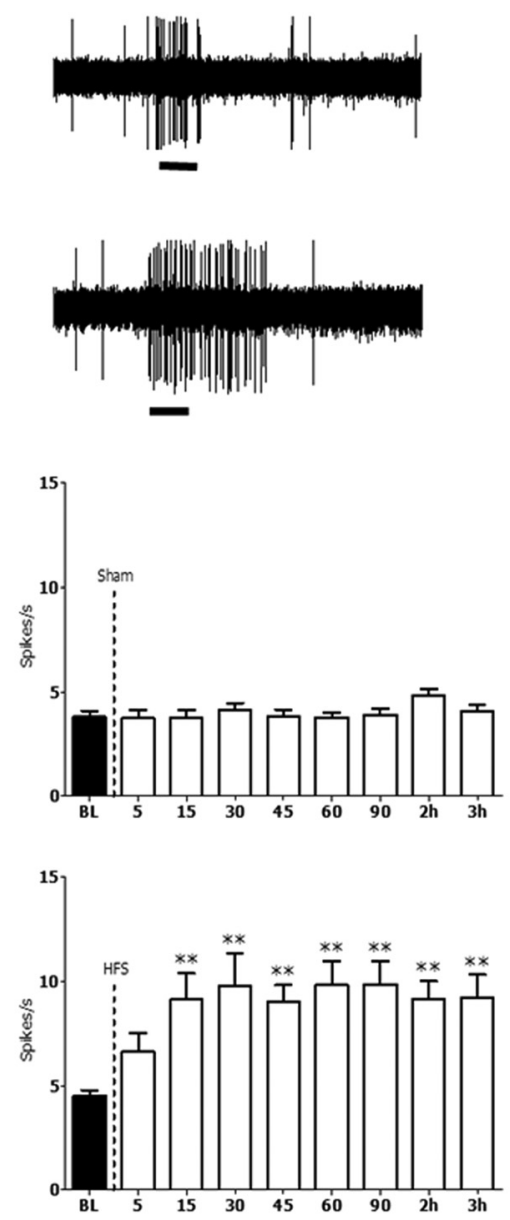

\section{Sciatic Nerve Stim.}
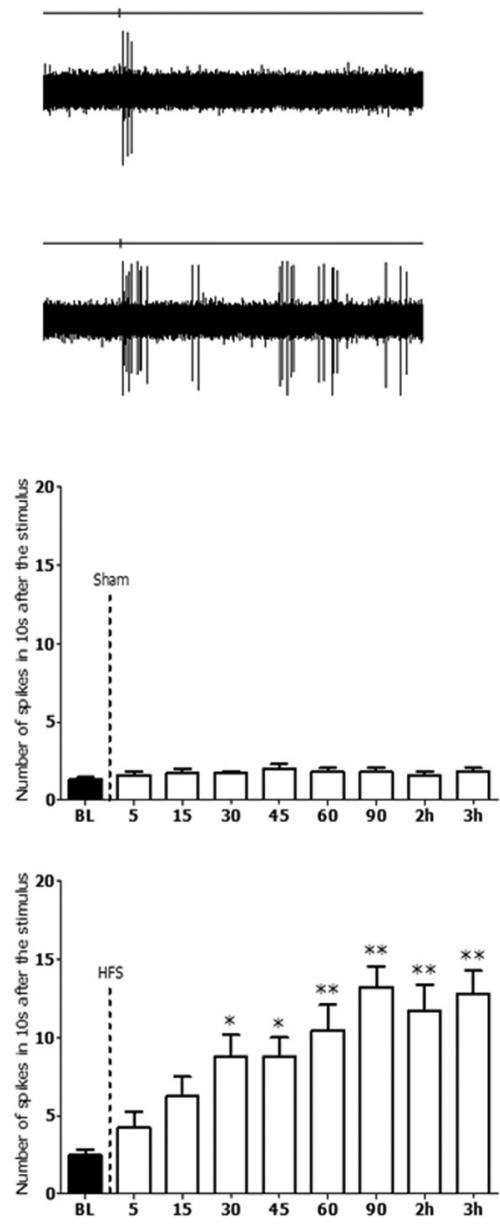

Figure 2. $\quad \boldsymbol{A}, \boldsymbol{B}$, Oscilloscope traces of innocuous (brush) and noxious (pinch, C-fiber stimulation of sciatic nerve) stimuli on spike activity of a thalamic VPL neuron before ( $\boldsymbol{A}$ ) and after HFS ( $\boldsymbol{B}$ ). Note the characteristic spike responses after each stimulus. Following sham, brush and pinch responses were indistinguishable versus their control response. High-frequency after-discharges occurred following each stimulus type after HFS. C, D, Histogram plots depicting the time course effect of sham HFS $(\boldsymbol{C})$ and HFS (D) on brush, pinch, and sciatic nerve "C-fiber" stimulus-evoked response magnitude of thalamic VPL neurons. Each histogram bar represents the group mean ( \pm SEM) response in spikes per stimulus application at different time points for all VPL neurons tested ( $n=40$ ). Note the marked and sustained enhancement in innocuous and noxious stimulus-induced VPL response magnitude following HFS ( $n=30$ neurons in 15 rats) but not sham HFS ( $n=10$ neurons in 7 rats, ${ }^{*} p<0.05,{ }^{* *} p<0.01$, one-way ANOVA, Dunn's multiple-comparison test).

stimuli applied to the sciatic nerve were replaced by marked afterdischarges following HFS.

For all thalamic neurons examined, a $>2$-fold increase in magnitude of brush, pinch, and sciatic responses occurred following HFS, which lasted well beyond the post-HFS recording time of $3 \mathrm{~h}$ (Fig. $2 D$; one-way ANOVA: Friedman test, $p=0.0001$ for each: brush, pinch, and pulse). Additional control experiments in a separate population of VPL neurons revealed that the magnitude of brush, pinch, and sciatic responses remained stable over the same $3 \mathrm{~h}$ period following sham HFS stimuli, i.e., when HFS at zero stimulus intensity was applied to the sciatic nerve (Fig. 2C; one-way ANOVA: Friedman test: $p=0.192$ brush, $p=$ 0.3722 pinch, and $p=0.8450$ pulse).

\section{Ongoing spike activity of VPL neurons: effect of HFS}

Under baseline conditions of 1.5\% isoflurane, and in the absence of peripherally applied stimuli, thalamic WDR neurons displayed little or no ongoing spike activity. The average spike rate measured $<0.12 \pm 0.04$ spikes/s for all cells recorded (Fig. $3 A$ ). Following HFS, but not sham HFS, thalamic spontaneous VPL neuron firing rate gradually increased over a $3 \mathrm{~h}$ period to a maximum of $1.15 \pm 0.29$ spikes/s (Fig. 3A; one-way ANOVA: Friedman test: $p<0.0001$ ). Approximately one-third of the recorded VPL neurons spontaneous discharges occurred as multiple spike bursts consisting of two or more action potentials (Fig. $3 B$ ) lasting a mean duration of $5.8 \pm 2.1$ ( \pm SEM), $19.4 \pm 4.2$, and $22.9 \pm 6.7 \mathrm{~ms} 1,2$, and $3 \mathrm{~h}$ after HFS, respectively. The number of action potentials within an individual spike burst varied from one event to another, across all animals. Therefore, HFS stimulation of the sciatic nerve leads to changes in thalamic VPL neurons that, in turn, allow these cells to fire more easily in a burst-like fashion (Fig. 3B).

Thalamic VPL neuron responsiveness to juxtacellular glutamate ejections

The HFS-induced enhancement in ongoing and evoked thalamic VPL neuron excitability may arise as a consequence of alterations in the properties of thalamic VPL neurons. We addressed this issue indirectly by comparing the GLU-evoked responsiveness of 10 thalamic neurons around HFS. An example of one VPL neuron responding to pulsatile ejections of GLU before and after HFS is illustrated in Figure $4 A$ and $B$. Note as in this example and for each remaining cell tested, the magnitude of the GLU-evoked response 
A

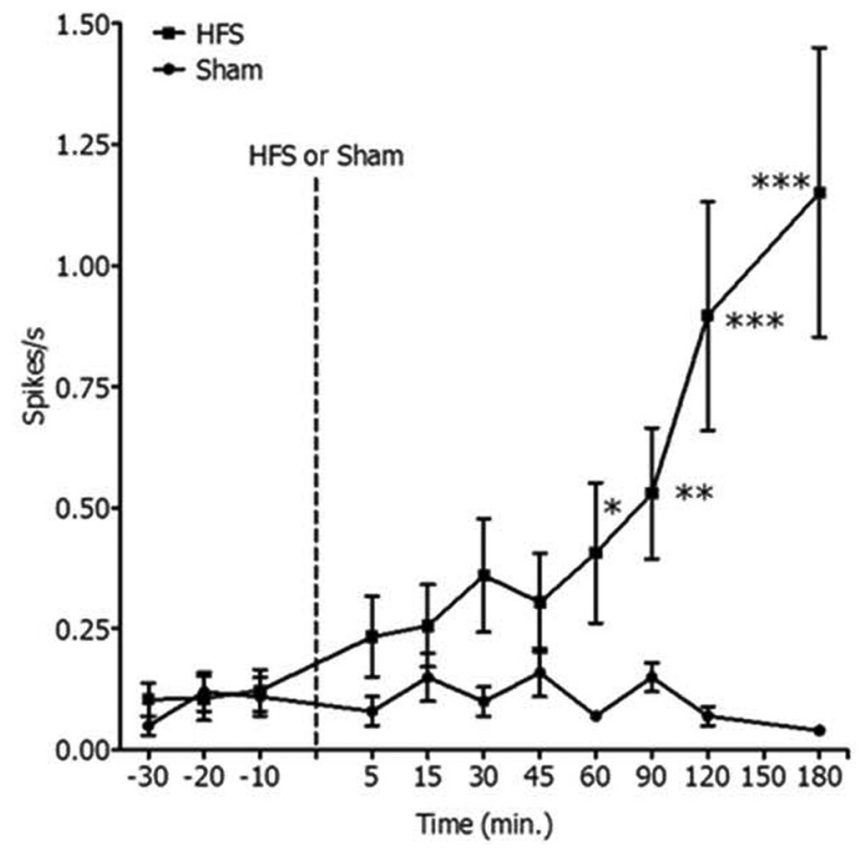
VPL Neurons Spontaneous
Spike Activity

B

Figure 3. $A$, Effect of HFS and sham stimuli applied to sciatic nerve on thalamic VPL neuron spike rate in the isoflurane-anesthetized rat preparation. Baseline spike rate ( $n=30$ neurons in 15 rats) was $<0.25 \mathrm{~Hz}$ and gradually increased following HFS but not sham HFS ( $n=10$ neurons in 7 rats; ${ }^{*} p<0.05 ;{ }^{* *} p<0.01$, ${ }^{* * *} p<0.001$, Dunn's multiple-comparison test). $\boldsymbol{B}$, Effect of HFS stimuli applied to the sciatic nerve on thalamic VPL neuron spike burst event activities. Each histogram bar represents the mean \pm SE of the number of events detected in a 4 min epoch under baseline pre-HFS conditions and $2 \mathrm{~h}$ following HFS stimuli in 30 neurons. Note that before HFS stimuli, very few burst events occurred (white histogram bars) that consisted of three or four action potentials. However, following HFS, the mean number of burst events and the number of action potentials per burst increased dramatically as did the number of action potentials per burst event.

was markedly enhanced following HFS for the remainder of each recording experiment. As illustrated in Figure 4, $C$ and $D$, the overall mean $( \pm$ SEM $)$ magnitude of GLU-evoked responses increased threefold from a control rate of $9.6 \pm 3.3 \mathrm{~Hz}$ during the peak of the GLU response to $26.2 \pm 6.5 \mathrm{~Hz}$ after HFS ( $p=0.017$, Mann-Whitney sum test). Figure $4 E$ also clearly illustrates that the onset of the GLU responses, i.e., time to 50\% maximum, was $\sim 36 \%$ faster while the slope of the GLU response onset (Fig. $4 G$ ) was $\sim 49 \%$ steeper, following HFS $(p<0.05)$. Overall in these 10 VPL neurons examined with juxtacellular applications of GLU, the time to 50\% maximum (Fig. $4 F$ ) and 10-90\% slope of the response onset (Fig. 4H), measured $7.2 \pm 0.9 \mathrm{~s}$ and $1.07 \pm 0.53$ before HFS while after HFS, these parameters measured $4.6 \pm 0.9 \mathrm{~s}$ and $2.1 \pm 0.4$, respectively (time to $50 \%: p=0.037$, slope: $p=0.021$, Mann-Whitney sum test). These data correspond to an overall $56 \%$ faster response onset and a 96\% steeper slope, and also provide indirect evidence that HFSinduced enhancement of GLU responses results, in part, in marked alterations of the postsynaptic membrane of thalamic VPL neurons.

\section{Cortical neuron excitability: HFS actions on EEG activity}

Baseline EEG data were collected at the same depth of anesthesia ( $1.5 \%$ isoflurane) in each of the same experiments where VPL neuron activities were described above. The baseline control, left and right parietal EEG were characterized by classical burstsuppression waveform activity, an example of which is presented in Figure 5A. Burst-suppression in Figure 5 occurs as a biphasic EEG pattern consisting of high-amplitude slow waves (burst) and followed by a period of flat EEG (suppression) (Swank and Watson, 1949). FFT power spectra analyses revealed little or no relative power in any of the classical bandwidths, e.g., $\delta(0-4 \mathrm{~Hz}), \theta$
$(4-8 \mathrm{~Hz}), \alpha(8-12 \mathrm{~Hz})$, and $\beta(12-30 \mathrm{~Hz})$ under control conditions (Fig. 5B). However, following HFS, the interval between subsequent EEG burst-suppression events shortened rapidly whereby EEG wave activity transformed to a unique pattern consisting predominantly of repetitively occurring, large- and smallamplitude "slow" waves. This large-amplitude, slow-wave EEG signature following HFS always occurred before any aforementioned changes in VPL neuron activity, within 5 min following HFS, reached a maximum within $15 \mathrm{~min}$, and was sustained $(\sim 3$ h) for the remainder of the experiment. Figure $5 B$ illustrates time course of change in power spectra for $\delta, \theta, \alpha$, and $\beta$ bandwidths in experiments where HFS and sham HFS were applied to the sciatic nerve. HFS increased power in each of these bandwidths, but the greatest magnitude power change occurred with the shortest onset bilaterally in the $\delta$ and the $\theta$ bandwidths. Power values in $\alpha$ and $\beta$ bandwidths increased substantially and were significantly different from baseline but at 2-3 h after HFS. When compared with their corresponding baseline, the power spectra in the $\delta$ and $\theta$ bandwidth increased onefold over the $3 \mathrm{~h}$ recording period following sham HFS (Fig. 5B). In two sham experiments baseline data collection was prolonged for $>2 \mathrm{~h}$ without peripheral stimulation and the classical burst-suppression waveform EEG activity remained intact (data not shown). However, following HFS, $\delta$ and $\theta$ power increased 20 - and 21 -fold, respectively, which was sustained throughout the entire recording period.

Thalamic VPL neuron and cortical EEG changes following HFS: effect of “depotentiation" stimuli

Tetanic sciatic nerve stimuli, at intensities that do not recruit C-fibers, prevent the induction or abolish established spinal LTP. 
A

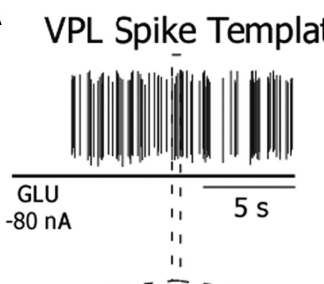

V'PL Spike Activity

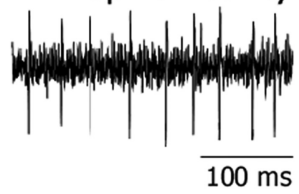

C

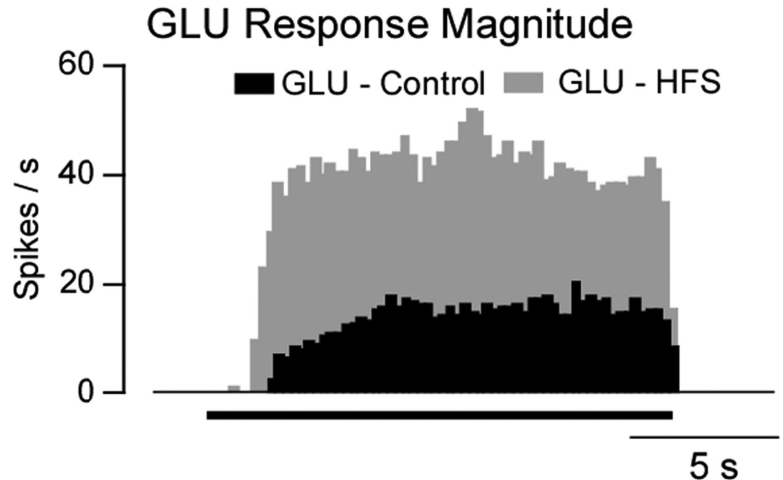

E

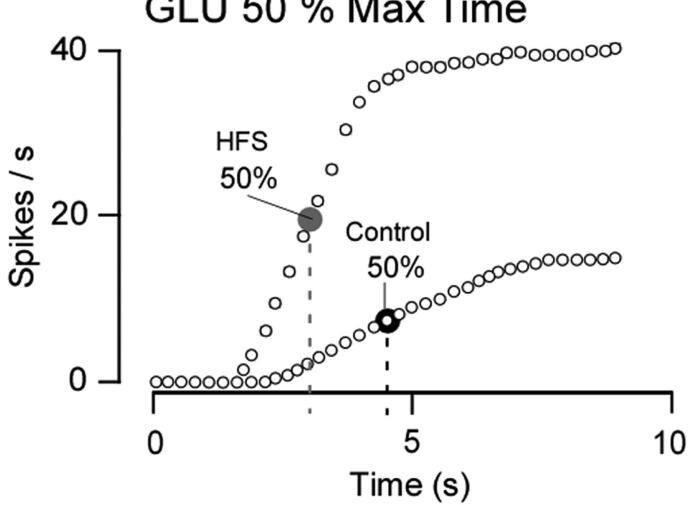

G

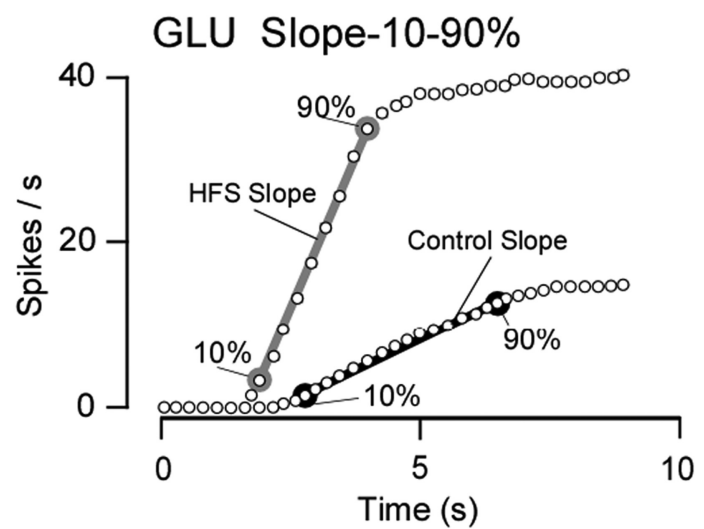

B VPL Neuron Consecutive GLU Responses - Control

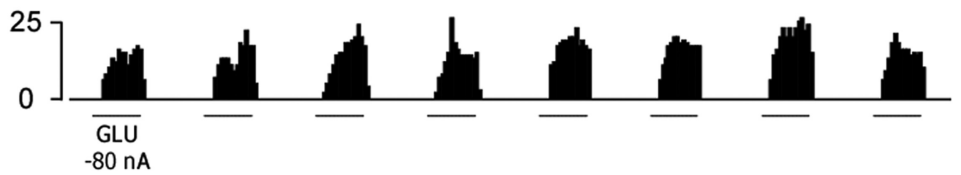

VPL Neuron Consecutive GLU Responses - HFS

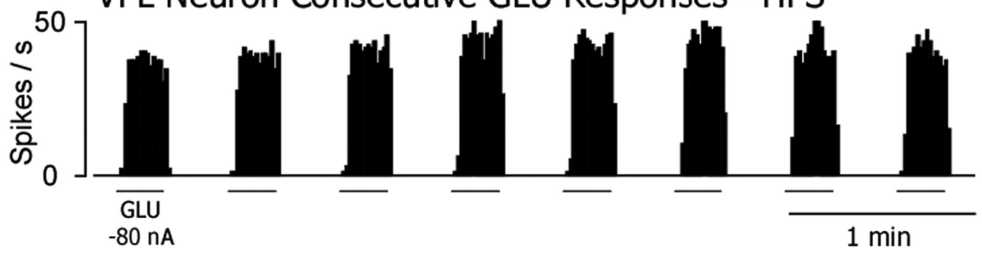

D

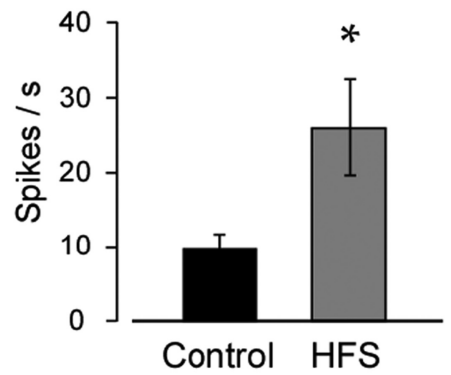

$\mathbf{F}$

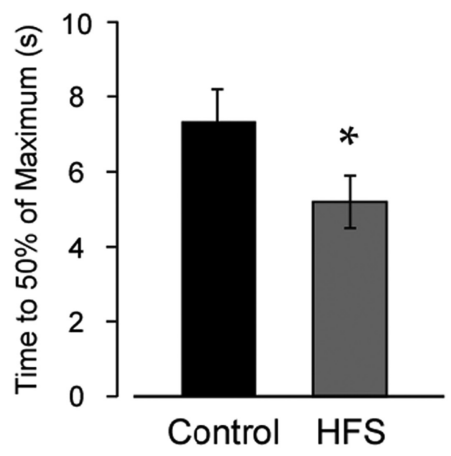

H

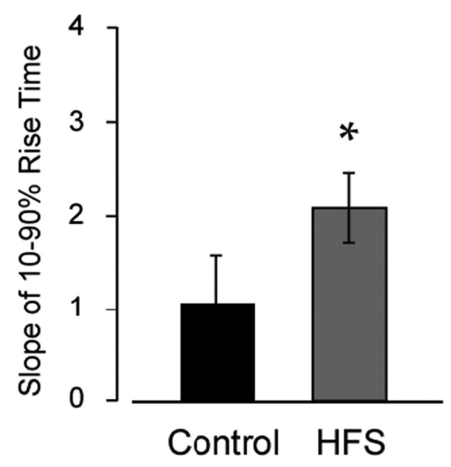

Figure 4. HFS enhancement of GLU-evoked excitations of thalamic VPL neurons. $\boldsymbol{A}$, The top left traces represent oscilloscope traces of a single VPL neuron's spike activity and spike template recorded in spike acquisition software during a single GLU pulse ejection. $\boldsymbol{B}$, The rate meter traces of pulsatile GLU ejections on the same VPL neuron over a 5 min period before and 30 min after $H F S$. Note the marked increase in consecutive GLU-evoked responses following HFS. The overall time course of the HFS effect on GLU response magnitude overlapped with that for pinch, brush, and C-fiber evoked responses, see Figure 2. C, The time expanded rate-meter plots reflect computer-averaged (bin by bin) plots of the eight individual GLU-responses in $\boldsymbol{B}$. $\boldsymbol{E}$, HFS also significantly shortened the $50 \%$ time to maximum response $(\boldsymbol{E})$ and steepened the slope of the rising phase $(\boldsymbol{G})$ of excitation by juxtacellular glutamate in this neuron. The histogram bars in $\boldsymbol{D}, \boldsymbol{F}$, and $\boldsymbol{H}$ represent the group mean ( \pm SEM) average magnitude, $50 \%$ time to max and slope of the response onset to GLU, respectively, for $10 \mathrm{VPL}$ neurons in six rats before and after HFS $\left({ }^{*} p<0.05\right.$, Mann-Whitney rank sum test). 
A

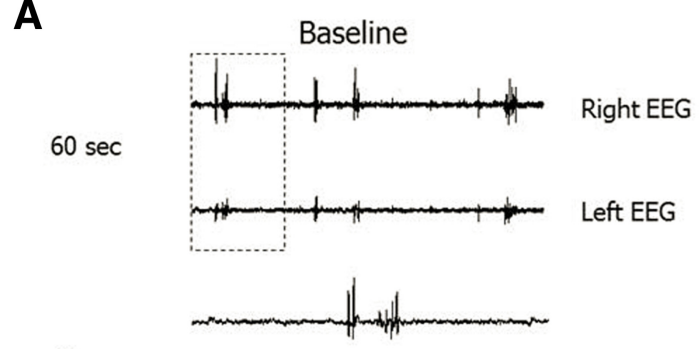

$15 \mathrm{sec}$

from the inset
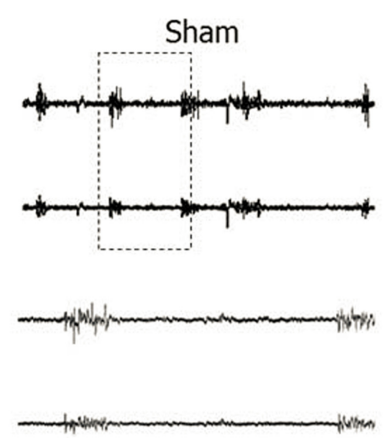

HFS

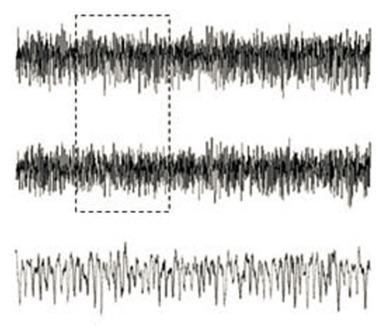

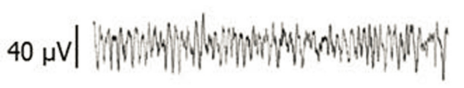
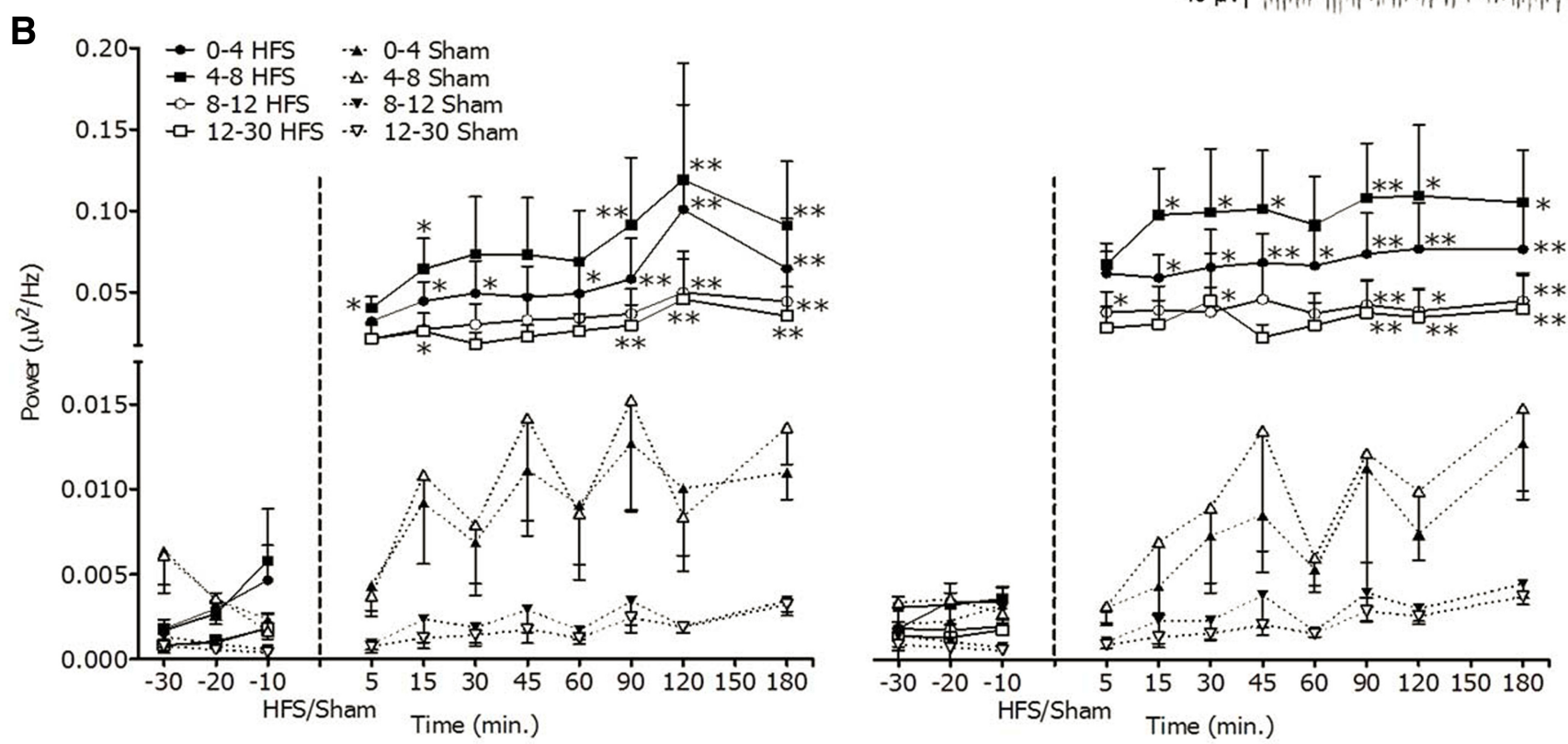

Figure 5. Effect of HFS on EEG waveform activity in the isoflurane-anesthetized rat preparation. $A$, Examples of EEG activity $(60 \mathrm{~s})$ recorded from the right and left parietal cortex under control baseline (top left), sham (top middle, $n=7$ rats), and $1 \mathrm{~h}$ following HFS (top right, $n=15$ rats) from one experiment. Lower two traces in $A$ are time-expanded views of the EEG activity encompassed by the dashed boxed enclosures to illustrate the burst-pause baseline EEG waveform signature replaced by a permanent pattern of recurring, large-amplitude slow waves following HFS. $\boldsymbol{B}$, Time course plots illustrating group mean ( \pm SEM) FFT power of left and right parietal cortical EEG activity in $\delta(0-4 \mathrm{~Hz}), \theta(4-8 \mathrm{~Hz}), \alpha(8-12 \mathrm{~Hz})$, and $\beta(12-30 \mathrm{~Hz})$ bandwidths from all experiments where HFS was used ( $n=15 ;{ }^{*} p<0.05,{ }^{* *} p<0.01$, one-way ANOVA, Dunn's multiple-comparison test). Sustained power increases were noted in $\delta$ and $\theta$ bandwidths within 5 min post HFS bilaterally compared with corresponding baseline ( -30 to $-10 \mathrm{~min}$ ), which lasted throughout the entire experiment. Significant and sustained increases in $\alpha$ and $\beta$ power occurred 2 and $3 \mathrm{~h}$ post-HFS. There were no significant changes in EEG activity following sham stimuli. Immediately following HFS, the right EEG $\delta$ and $\theta$ power increased by 20 -and 21 -fold while the left $\delta$ and $\theta$ power increased 10- and 12-fold, respectively, when compared with baseline.

This latter finding is known as LTD (Liu et al., 1998; Sandkühler, 2007). We refer to this herein as depotentiation and it is not known if such spinal depotentiation mechanisms influence the thalamus and cortex in a similar fashion. Therefore, we examined this possibility by first inducing the enhanced excitability of thalamic VPL neurons and slow-wave EEG signature following HFS described herein. We then applied the low-intensity stimulus train $(10 \mathrm{~V}, 0.1 \mathrm{~ms}$ pulses, $100 \mathrm{~Hz}, 1.0 \mathrm{~s}$ duration at $10 \mathrm{~s}$ intervals for $15 \mathrm{~min}$ ) that are claimed to activate $\mathrm{A} \alpha$-, $\beta$-, and $\delta$-fibers in the sciatic nerve (Liu et al., 1998; Sandkühler, 2007) and reassessed thalamic VPL neuron excitability and EEG activity. Depotentiation-inducing stimuli did not alter HFS-induced enhancement of thalamic WDR neuron excitability (Friedman test: $p=0.6626$ brush, $p=0.7358$ pinch, $p=0.3917$ pulse, and $p=$ 0.9476 ongoing activity; Fig. 6). Moreover, depotentiation stimuli further did not alter the cortical EEG power in $\delta(0-4 \mathrm{~Hz})$ and $\theta(4-8 \mathrm{~Hz})$ bandwidths that was already increased following HFS. A second depotentiation stimulus train presentation also failed to alter power in $\delta$ and $\theta$ bandwidths without affecting WDR-VPL neuronal excitability (Friedman test: $p=0.7682$, for left $\delta$ and right $\delta, p=0.6197$ for left $\theta$, and $p=0.7682$ for right $\theta$, respectively; Fig. 7). Depotentiation stimuli alone had no effect (data not shown). These data indicate that sciatic nerve stimuli that reverse spinal LTP affected by HFS are not extended to thalamic VPL neurons and cortical EEG.

\section{Thalamic VPL neuron recording sites}

Thalamic recording sites in the posterior thalamus were confirmed from stereotaxic coordinates of neuron recordings against a reference electrolytic lesion made at the end of the experiments. Figure 8 depicts composite anatomical locations of the sites for each rat where WDR neurons were recorded. All were confirmed within the VPL nucleus according to the rat brain atlas of Paxinos and Watson (2007).

\section{Discussion}

The present findings provide long-standing missing links between the phenomena of spinal LTP induced by intense tetanic sciatic nerve stimulation and its upstream consequences on sensory inflow through classical thalamocortical networks. Specifi- 
A

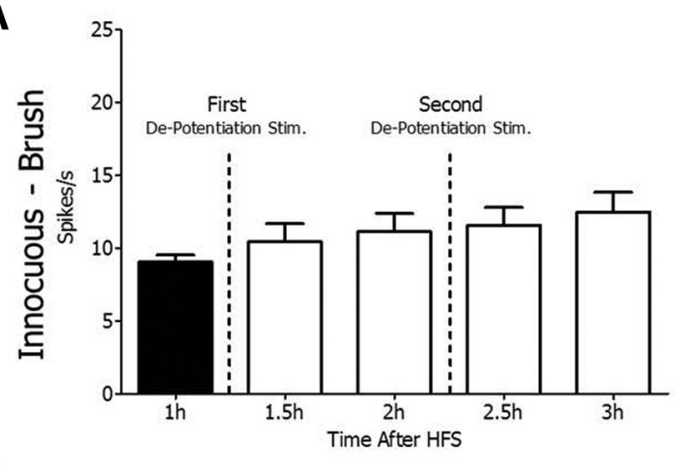

C

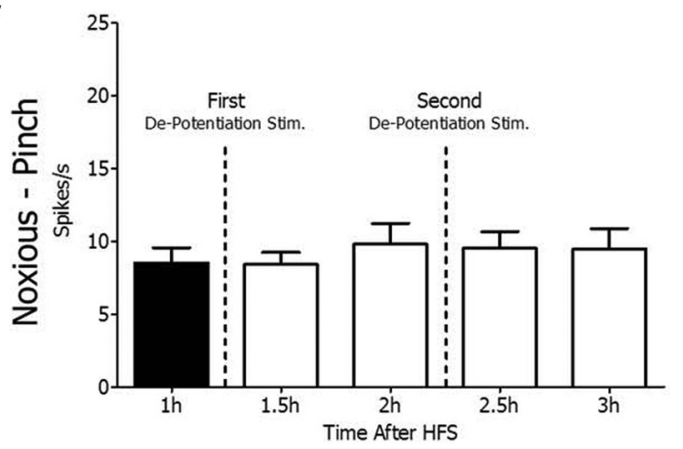

B

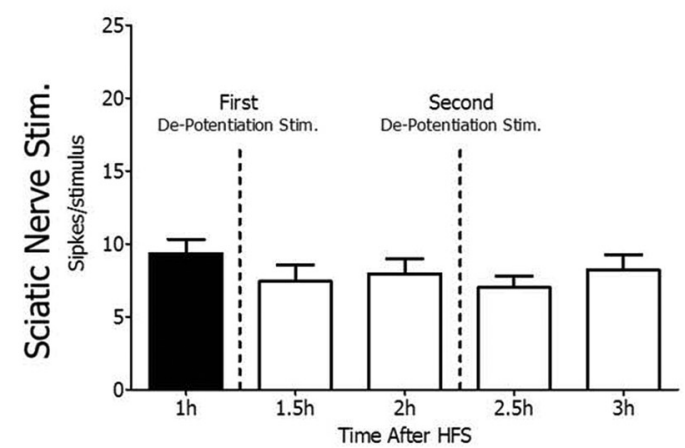

D

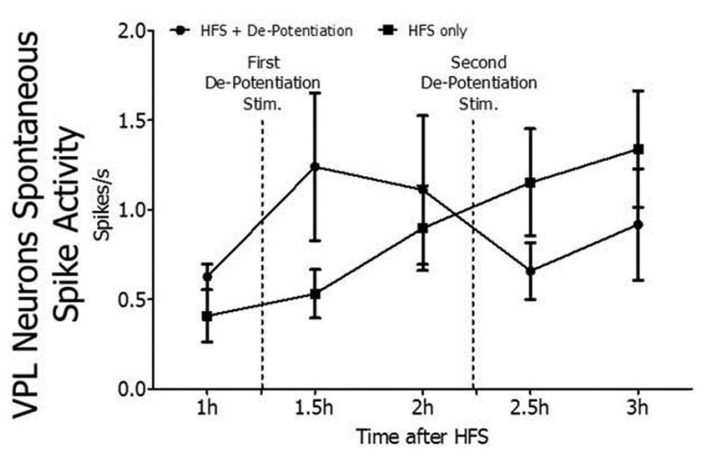

Figure 6. A, Resilience of enhanced thalamic VPL neuron activity following HFS to depotentiation stimuli (Liu et al., 1998; Sandkühler, 2007). The solid histogram bars in $\boldsymbol{A}-\mathbf{C}$ depict the group mean ( \pm SEM) thalamic VPL neuron responses to brush $(\boldsymbol{A})$ and sciatic nerve " $C$-fiber" stimulus-evoked response magnitude $(\boldsymbol{B})$, as well as pinch $(\boldsymbol{C})$. Each open histogram bar represents the group mean response in spikes per stimulus application over a $4 \mathrm{~h}$ epoch for all VPL neurons tested $(n=14)$ after initial or secondary spinal depotentiation stimuli. Depotentiation stimuli did not alter evoked (one-way ANOVA: Friedman test: $p>0.05$ for brush, pinch, and sciatic nerve $C$-fiber stimuli) or ongoing spike activities (D) in 14 neurons examined in seven rats.

A

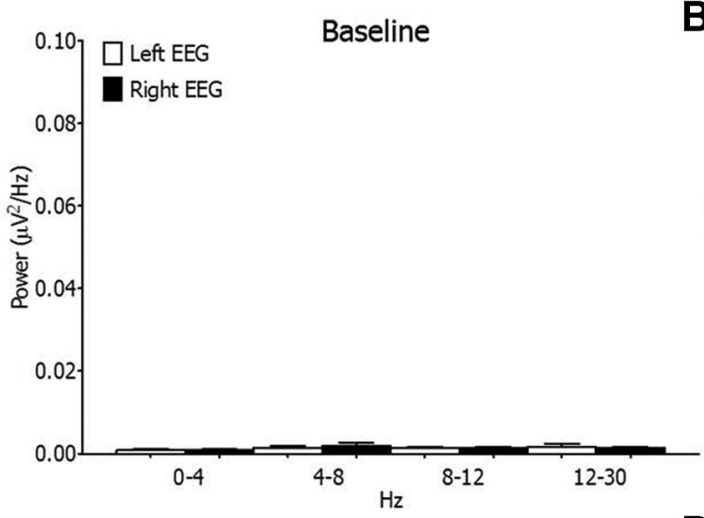

C

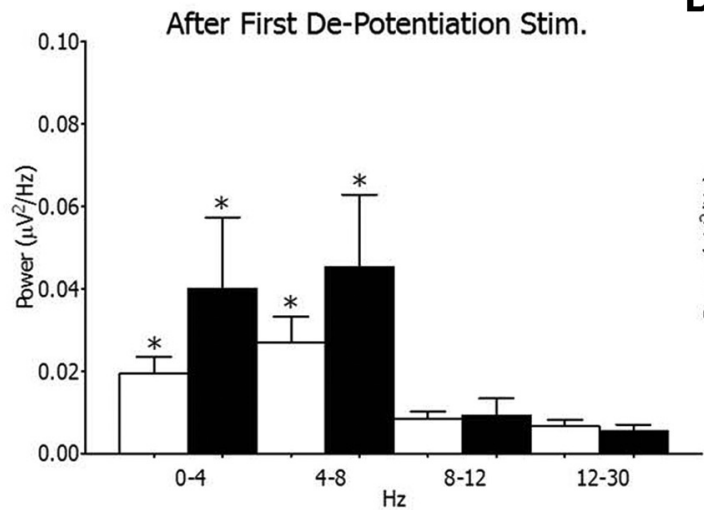

B

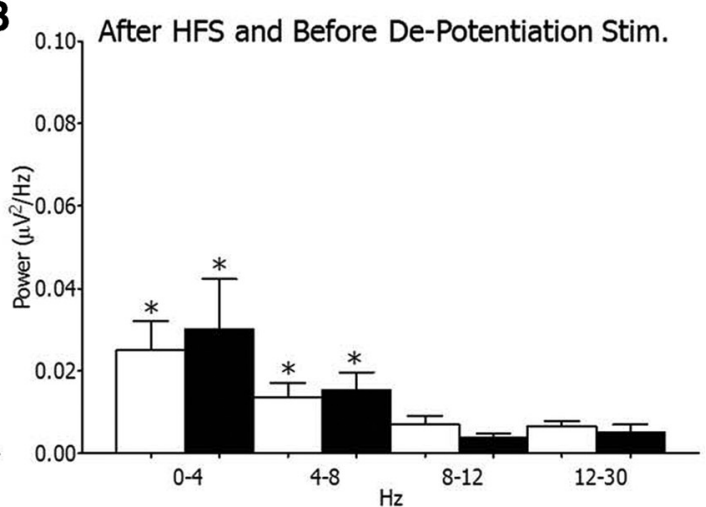

D

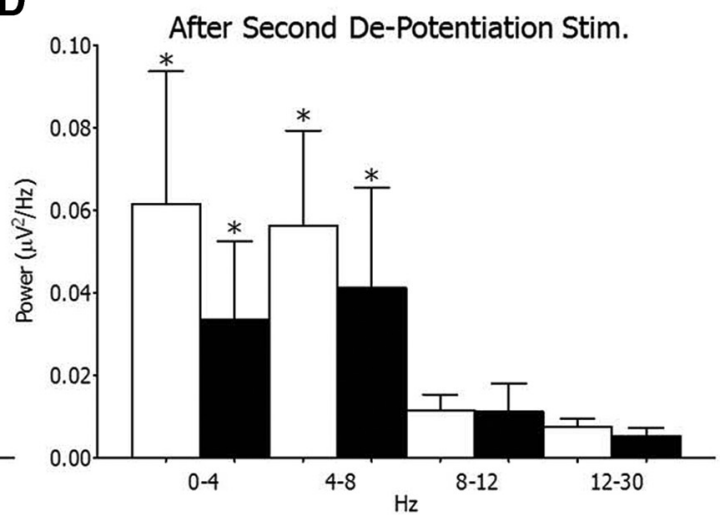

Figure 7. FFT power plots of EEG activity before $(\boldsymbol{A})$ and after HFS ( $\boldsymbol{B})$, and subsequently after depotentiation stimuli applied to the sciatic nerve $(\boldsymbol{C}, \boldsymbol{D})$. Data are expressed as histogram bars representing the group mean ( \pm SEM) powervalues for respective bandwidths around HFS stimuli and depotentiation stimuli. $\boldsymbol{A}$, Baseline power values in $\delta$ and $\theta$ bands undergo a marked increase following HFS (in $\boldsymbol{B}-D$ : ${ }^{*} p<$ 0.05 , one-way ANOVA, Dunn's multiple-comparison test vs corresponding values in $\boldsymbol{A}$ ). The first trial of depotentiation stimuli $(\boldsymbol{C})$ did not alter $\delta$ and $\theta$ bandwidth power versus that which was consistently observed following HFS. A second trial of depotentiation stimuli ( $\boldsymbol{D}$ ) also did not alter $\delta$ and $\theta$ bandwidths ( $p>0.05$, one-way ANOVA, Dunn's multiple-comparison test). 

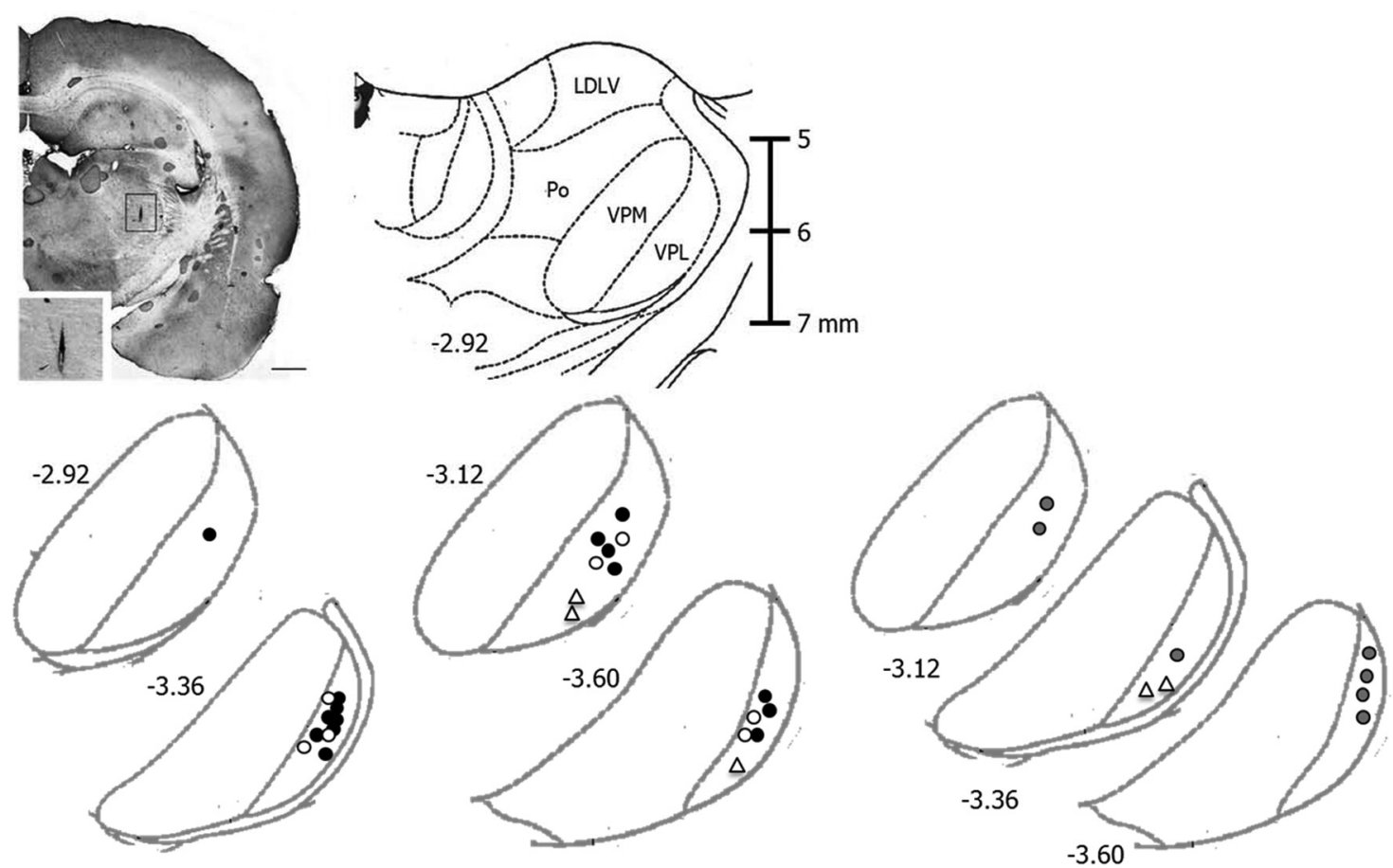

○ Sham recordings

- Experimental HFS recordings

- Experimental LTD recordings $\Delta$ Microiontophoretic GLU recordings

Figure 8. Localization of recording sites of WDR units in the rat thalamus. Photomicrograph on the upper left shows an example of a lesion site (boxed enclosure). Drawings show localization of VPL neurons recorded in each experiment. Coronal sections adapted from the atlas of Paxinos and Watson (2007). Numbers indicate distance in millimeters from bregma. Scale indicates distance from the cortex. Thalamic nuclei: VPM/L, ventro-postero-medial/lateral; LDVL, latero-dorsal, ventro-lateral; Po, post-thalamic group.

cally, VPL neuron activity and cortical activity reported herein were dramatically and irreversibly modified by identical intense HFS used by Sandkühler et al. over the past 15 years to induce spinal LTP (Liu and Sandkühler, 1995, 1997; Svendsen et al., 2000; Sandkühler, 2007). These HFS-induced supraspinal modifications are reflected by the development of enhanced, longlasting VPL neuron excitability and cortical synchronization.

\section{General properties of thalamic VPL neurons around HFS conditioning stimuli during isoflurane anesthesia}

All thalamic neurons recorded in this study were located at sites corresponding to the thalamic VPL nucleus and were characterized by their responses to non-noxious (brush) and noxious (pinch; intense sciatic nerve stimulation) stimuli applied to the contralateral hindlimb. Under isoflurane anesthesia, the lowlevel baseline spontaneous spike activity and response characteristics of WDR neurons in the present study coincided with that of WDR thalamic VPL neurons reported previously (Sherman et al., 1997; Gerke et al., 2003; Hains et al., 2006; Iwata et al., 2011).

A principal finding of the present study was that following HFS, thalamic VPL neurons underwent a slow-onset increase in cellular excitability. Following HFS, but not sham HFS, spontaneous, pinch, and peripheral nerve-evoked (C-fiber) responses of thalamic VPL WDR neurons were all markedly enhanced within 5,15 , and $30 \mathrm{~min}$, respectively, and remained so in excess of $3 \mathrm{~h}$. Moreover, following HFS, brush-evoked responses of recorded VPL neurons were also enhanced. This latter observation recapitulates the findings reported by of Svendsen et al. (1997) that HFS enhanced the oligosynaptic responses of dorsal horn neurons driven by $\mathrm{A} \beta$ afferent fibers. Our data further confirms that HFS profoundly impacts classical supraspinal structures comprising the pain matrix (Legrain et al., 2011; Saab, 2012). It also appears that HFS-induced spinal LTP impacts the somatosensory cortex and VPL nucleus much sooner than other higher brain areas, e.g., the triangular posterior nucleus (González-Hernández et al., 2013).

In the present study, glutamate-evoked responses were also markedly enhanced following HFS. Glutamate is known to exert its excitatory actions postsynaptically in the CNS on most cells in which it has been tested (Puil, 1981; Salt and Eaton, 1996). In the present study, it is likely that HFS enhances thalamic VPL neuron responses to microiontophoretic pulsatile ejections of glutamate in part by enhancing postsynaptic excitatory transmission between ascending sensory tract neurons or corticothalamic neurons, and the somatic and proximal dendrites of the VPL neurons under study. Possible postsynaptic mechanisms include but are not limited to a reduction in VPL neuron postsynaptic inhibition, vis a vis a shift in normal inhibition to excitation, and/or excitatory receptor sensitization, etc. Additional studies will be needed to differentiate between these and other possible mechanisms.

The magnitude of increase in ongoing VPL neuron activity and spike burst activities following HFS was much lower than that reported by Saab et al. (Iwata et al., 2011) and may likely be due to differences between their studies and ours in the length of time following test conditions. For example, Iwata et al. (2011) recorded thalamic neuron activity $7 \mathrm{~d}$ following a chronic constriction injury of the sciatic nerve whereas our neurons were monitored immediately after and up to $4-5 \mathrm{~h}$ following HFS. Future studies are warranted to verify this possibility. 


\section{Cortical EEG activity around HFS conditioning stimuli during isoflurane anesthesia}

All previous in vivo animal studies of spinal LTP following HFS (Benrath et al., 2004; Sandkühler, 2007) as well as the current investigation were conducted by necessity under general anesthesia. Indeed, the study of Benrath et al. (2004) and the present study may be considered equivalent regarding the depth of isoflurane anesthesia and HFS parameters used. The principal difference with our study is that it is the first to focus on thalamic VPL neurons and cortical EEG changes around HFS.

Spectral analyses of parietal EEG activity during burst suppression in baseline recordings before HFS or 3-4 h following sham stimuli revealed low power in the $\delta, \theta, \alpha$, and $\beta$ frequency bands indicating a stable state of isoflurane anesthesia (Swank and Watson, 1949; Kroeger and Amzica, 2007). Within 5 min following HFS, the EEG was dominated by continuous largeamplitude, slow waves in $\delta$ and $\theta$ bandwidths. Sustained power increases in $\alpha$ and $\beta$ bands also occurred that were intermixed with dominant slower $\delta$ and $\theta$ bands.

Emergence from the state of isoflurane anesthesia is associated with decreased power in $\delta, \theta, \alpha$, and $\beta$ bands (Kortelainen et al., 2012), and cannot explain our observed HFS actions on EEG pattern. Similarly, the phenomenon of paradoxical arousal during anesthesia, whereby intense surgery causes momentary increased $\delta$ and decreased $\alpha$ band activities (Kochs et al., 1994; Otto and Mally, 2003), also cannot account for the long-lasting HFSinduced change in EEG pattern in the present study. In related work, we have observed long-lasting, marked $\delta$ and $\theta$ power in the parietal EEG of awake animals following the characteristic biphasic, behavioral motor syndrome induced by intraplantar injections of formalin (Sanoja et al., 2012). It therefore appears that thalamo-cortical-thalamic networks undergo dynamic changes as a consequence of intense afferent inflow caused by classical spinal LTP-inducing HFS stimuli.

\section{Relative sensitivity of thalamocortical networks versus spinal networks to (de)-potentiating stimuli}

Liu et al. (1998) reported that conditioning stimuli at A $\delta$-fiber strength applied to the sciatic nerve in spinally intact animal preparations, depressed LTP, i.e., increased C-fiber amplitude, produced by HFS. In the present study, enhanced thalamic VPL neuron excitability following HFS or cortical synchronization was not reduced after the same depotentiating ( $\mathrm{A} \delta$-fiber strength) stimuli used by Liu et al. (1998) were delivered repeatedly to the sciatic nerve. The actions of depotentiating stimuli on established spinal LTP appear to be confined to the spinal cord. This resilience of enhanced thalamocortical transmission to depotentiating stimuli may partly underlie the observation in clinical studies where patients fail to obtain adequate relief of chronic pain when afferent stimulation protocols were used (Rao et al., 1981; Mobbs et al., 2007).

Studies of spinal LTP have transected the spinal cord to remove tonic supraspinal inhibition which, in turn, reduces the magnitude of LTP (Liu and Sandkühler, 1998; Liu et al., 1998; Gjerstad et al., 2001). Accordingly, under our experimental conditions where the spinal cord remained intact, tonic supraspinal inhibition, would be expected to dampen spinal neuron excitability around HFS. Peripherally applied stimuli around HFS would also be expected to impact thalamocortical networks, via sensory inflow through ascending projection pathways.

These points, together with our findings, infer that under conditions where the spinal cord remains intact, thalamocortical VPL neurons are impacted by HFS along with spinal cord dorsal horn neurons (Sandkühler, 2007). Spinal LTP has been proposed as a mechanism underlying hyperalgesia (Liu and Sandkühler, 1997; Ikeda et al., 2006; Sandkühler, 2007) and HFS applied to the sciatic nerve in anesthetized rats exert lingering postoperative hyperalgesia lasting up to 1 week (Hitomi et al., 2012) and beyond (Le et al., 2010). Our current findings suggest that HFS-induced thalamocortical changes may also contribute substantially to postoperative hyperalgesia (Le et al., 2010; Hitomi et al., 2012).

\section{Cortical synchronization and thalamic neuron excitability following HFS during isoflurane anesthesia versus thalamocortical dysrhythmia syndrome}

Thalamo-cortico-thalamic networks play key roles in the transmission of nociceptive input (Condés-Lara et al., 1996; Gerke et al., 2003; Fischer et al., 2009) as well as thalamocortical dysrhythmia syndrome (TCD) (Llinás et al., 1999). The cortical EEG of awake chronic pain patients with confirmed TCD syndrome consists of large-amplitude slow waves entrained in the $\delta$ and $\theta$ bandwidths (Llinás et al., 1999; Llinás, 2003; Sarnthein et al., 2006; Boord et al., 2008; Sarnthein and Jeanmonod, 2008; Walton and Llinas, 2010).

Thalamic neurons are also known to discharge in lowfrequency bursts in chronic pain patients (Lenz et al., 1989; Jeanmonod et al., 1996). In experimental animal models, VPL neurons fire spontaneously in bursts during a state of chronic pain (Condés-Lara et al., 1996; Gerke et al., 2003; Fischer et al., 2009). Additionally, the magnitude of peripherally evoked sensory responses of VPL neurons is also markedly enhanced during the chronic pain state (Gerke et al., 2003; Weng et al., 2003). Accordingly, it appears that normal sensory inflow through and network operations within the VPL and thalamus may malfunction when a state of chronic pain in experimental animals or TCD syndrome in humans (Llinás et al., 1999) exist. It remains to be determined if and how HFS alters normal thalamo-corticothalamic network operations thereby favoring a state shift toward abnormal TCD syndrome (Llinás et al., 1999).

\section{Conclusions}

In the isoflurane anesthetized rat preparation, high-intensity HFS conditioning of the sciatic nerve, which produces classical spinal LTP, exerts significant, heretofore unrecognized, longlasting enhancement in thalamic VPL neuron excitability. This occurs in conjunction with a shift of the cortical EEG from "burst suppression" to large-amplitude, slow-wave pattern resembling TCD syndrome. These HFS-induced changes are resilient to "depotentiating" stimuli that readily suppress established spinal LTP.

\section{References}

Benrath J, Brechtel C, Martin E, Sandkühler J (2004) Low doses of fentanyl block central sensitization in the rat spinal cord in vivo. Anesthesiology 100:1545-1551. CrossRef Medline

Boord P, Siddall PJ, Tran Y, Herbert D, Middleton J, Craig A (2008) Electroencephalographic slowing and reduced reactivity in neuropathic pain following spinal cord injury. Spinal Cord 46:118-123. CrossRef Medline

Condés-Lara M, Sanchez-Moreno RM, Omaña-Zapata I (1996) Cortical facilitatory action on centralis lateralis thalamic activity during the development of carrageenin-produced inflammation. Arch Med Res 27:265-273. Medline

Fischer TZ, Tan AM, Waxman SG (2009) Thalamic neuron hyperexcitability and enlarged receptive fields in the STZ model of diabetic pain. Brain Res 1268:154-161. CrossRef Medline

Gerke MB, Duggan AW, Xu L, Siddall PJ (2003) Thalamic neuronal activity in rats with mechanical allodynia following contusive spinal cord injury. Neuroscience 117:715-722. CrossRef Medline

Gjerstad J, Tjølsen A, Hole K (2001) Induction of long-term potentiation of 
single wide dynamic range neurones in the dorsal horn is inhibited by descending pathways. Pain 91:263-268. CrossRef Medline

González-Hernández A, Martínez-Lorenzana G, Rojas-Piloni G, RodríguezJiménez J, Hernández-Linares Y, Villanueva L, Condés-Lara M (2013) Spinal LTP induced by sciatic nerve electrical stimulation enhances posterior triangular thalamic nociceptive responses. Neuroscience 234:125-134. CrossRef Medline

Hains BC, Saab CY, Waxman SG (2006) Alterations in burst firing of thalamic VPL neurons and reversal by $\mathrm{Na}(\mathrm{v}) 1.3$ antisense after spinal cord injury. J Neurophysiol 95:3343-3352. CrossRef Medline

Herkenham M (1980) Laminar organization of thalamic projections to the rat neocortex. Science 207:532-535. CrossRef Medline

Hitomi S, Shinoda M, Suzuki I, Iwata K (2012) Involvement of transient receptor potential vanilloid 1 in ectopic pain following inferior alveolar nerve transection in rats. Neurosci Lett 513:95-99. CrossRef Medline

Ikeda H, Stark J, Fischer H, Wagner M, Drdla R, Jäger T, Sandkühler J (2006) Synaptic amplifier of inflammatory pain in the spinal dorsal horn. Science 312:1659-1662. CrossRef Medline

Iwata M, LeBlanc BW, Kadasi LM, Zerah ML, Cosgrove RG, Saab CY (2011) High-frequency stimulation in the ventral posterolateral thalamus reverses electrophysiologic changes and hyperalgesia in a rat model of peripheral neuropathic pain. Pain 152:2505-2513. CrossRef Medline

Jeanmonod D, Magnin M, Morel A (1996) Low-threshold calcium spike bursts in the human thalamus. Common physiopathology for sensory, motor and limbic positive symptoms. Brain 119:363-375. CrossRef Medline

Jensen KF, Killackey HP (1987) Terminal arbors of axons projecting to the somatosensory cortex of the adult rat. I. The normal morphology of specific thalamocortical afferents. J Neurosci 7:3529-3543. Medline

Jones EG (2007) The thalamus, Ed 2. New York: Cambridge UP.

Kochs E, Bischoff P, Pichlmeier U, Schulte am Esch J (1994) Surgical stimulation induces changes in brain electrical activity during isoflurane/nitrous oxide anesthesia. A topographic electroencephalographic analysis. Anesthesiology 80:1026-1034. CrossRef Medline

Kortelainen J, Jia X, Seppänen T, Thakor N (2012) Increased electroencephalographic gamma activity reveals awakening from isoflurane anaesthesia in rats. Br J Anaesth 109:782-789. CrossRef Medline

Kroeger D, Amzica F (2007) Hypersensitivity of the anesthesia-induced comatose brain. J Neurosci 27:10597-10607. CrossRef Medline

Le MK, Shin HJ, Yang GY, Yoon YW, Han SK, Bae YC, Ahn DK (2010) Intracisternal and intraperitoneal administration of morphine attenuates mechanical allodynia following compression of the trigeminal ganglion in rats. J Orofacial Pain 24:113-121. Medline

Legrain V, Iannetti GD, Plaghki L, Mouraux A (2011) The pain matrix reloaded: a salience detection system for the body. Prog Neurobiol 93:111-124. CrossRef Medline

Lenz FA, Kwan HC, Dostrovsky JO, Tasker RR (1989) Characteristics of the bursting pattern of action potentials that occurs in the thalamus of patients with central pain. Brain Res 496:357-360. CrossRef Medline

Liao CC, Yen CT (2008) Functional connectivity of the secondary somatosensory cortex of the rat. Anat Rec 291:960-973. CrossRef Medline

Liu X, Sandkühler J (1997) Characterization of long-term potentiation of C-fiber-evoked potentials in spinal dorsal horn of adult rat: essential role of NK1 and NK2 receptors. J Neurophysiol 78:1973-1982. Medline

Liu XG, Sandkühler J (1995) Long-term potentiation of C-fiber-evoked potentials in the rat spinal dorsal horn is prevented by spinal N-methyl-Daspartic acid receptor blockage. Neurosci Lett 191:43-46. CrossRef Medline

Liu XG, Sandkühler J (1998) Activation of spinal N-methyl-D-aspartate or neurokinin receptors induces long-term potentiation of spinal C-fibreevoked potentials. Neuroscience 86:1209-1216. CrossRef Medline

Liu XG, Morton CR, Azkue JJ, Zimmermann M, Sandkühler J (1998) Longterm depression of C-fibre-evoked spinal field potentials by stimulation of primary afferent A delta-fibres in the adult rat. Eur J Neurosci 10:30693075. CrossRef Medline

Llinás RR (2003) [Thalamo-cortical dysrhythmia syndrome: neuropsychiatric features]. An R Acad Nac Med 120:267-290; discussion 290-295. Medline

Llinás RR, Ribary U, Jeanmonod D, Kronberg E, Mitra PP (1999) Thalamocortical dysrhythmia: a neurological and neuropsychiatric syndrome characterized by magnetoencephalography. Proc Natl Acad Sci U S A 96: 15222-15227. CrossRef Medline
Manjarrez E, Rojas-Piloni G, Vazquez D, Flores A (2002a) Cortical neuronal ensembles driven by dorsal horn spinal neurones with spontaneous activity in the cat. Neurosci Lett 318:145-148. CrossRef Medline

Manjarrez E, Rojas-Piloni G, Martínez L, Vázquez D, Vélez D, Méndez I, Flores A (2002b) Amplitude of somatosensory cortical evoked potentials is correlated with spontaneous activity of spinal neurones in the cat. Neurosci Lett 323:187-190. CrossRef Medline

Mobbs RJ, Nair S, Blum P (2007) Peripheral nerve stimulation for the treatment of chronic pain. J Clin Neurosci 14:216-221; discussion 222-223. CrossRef Medline

Otto KA, Mally P (2003) Noxious stimulation during orthopaedic surgery results in EEG 'arousal' or 'paradoxical arousal' reaction in isofluraneanaesthetised sheep. Res Vet Sci 75:103-112. CrossRef Medline

Paxinos G, Watson C (2007) The rat brain in stereotaxic coordinates. San Diego: Academic.

Puil E (1981) S-Glutamate: its interactions with spinal neurons. Brain Res 228:229-322. Medline

Randić M, Jiang MC, Cerne R (1993) Long-term potentiation and longterm depression of primary afferent neurotransmission in the rat spinal cord. J Neurosci 13:5228-5241. Medline

Rao VR, Wolf SL, Gersh MR (1981) Examination of electrode placements and stimulating parameters in treating chronic pain with conventional transcutaneous electrical nerve stimulation (TENS). Pain 11:37-47. CrossRef Medline

Saab CY (2012) Pain-related changes in the brain: diagnostic and therapeutic potentials. Trends Neurosci 35:629-637. CrossRef Medline

Salt TE, Eaton SA (1996) Functions of ionotropic and metabotropic glutamate receptors in sensory transmission in the mammalian thalamus. Prog Neurobiol 48:55-72. CrossRef Medline

Sandkühler J (2007) Understanding LTP in pain pathways. Mol Pain 3:3-9. CrossRef Medline

Sanoja R, Huber E, Soja P (2012) Thalamocortical dysrhythmia induced by intraplantar formalin injection in the awake rat Neuroscience Meeting Planner. Soc Neurosci Abstr 38:318.04.

Saporta S, Kruger L (1977) The organization of thalamocortical relay neurons in the rat ventrobasal complex studied by the retrograde transport of horseradish peroxidase. J Comp Neurol 174:187-208. CrossRef Medline

Sarnthein J, Jeanmonod D (2008) High thalamocortical theta coherence in patients with neurogenic pain. Neuroimage 39:1910-1917. CrossRef Medline

Sarnthein J, Stern J, Aufenberg C, Rousson V, Jeanmonod D (2006) Increased EEG power and slowed dominant frequency in patients with neurogenic pain. Brain 129:55-64. Medline

Sherman SE, Luo L, Dostrovsky JO (1997) Altered receptive fields and sensory modalities of rat VPL thalamic neurons during spinal strychnineinduced allodynia. J Neurophysiol 78:2296-2308. Medline

Soja PJ, Fragoso MC, Cairns BE, Jia WG (1996) Dorsal spinocerebellar tract neurons in the chronic intact cat during wakefulness and sleep: analysis of spontaneous spike activity. J Neurosci 16:1260-1272. Medline

Soja PJ, Pang W, Taepavarapruk N, Cairns BE, McErlane SA (2001) On the reduction of spontaneous and glutamate-driven spinocerebellar and spinoreticular tract neuronal activity during active sleep. Neuroscience 104: 199-206. CrossRef Medline

Steriade M (2003) The corticothalamic system in sleep. Front Biosci 8:d878-899. CrossRef Medline

Svendsen F, Tjølsen A, Hole K (1997) LTP of spinal A-beta and C-fibre evoked responses after electrical sciatic nerve stimulation. Neuroreport 8:3427-3430. CrossRef Medline

Svendsen F, Hole K, Tjølsen A (2000) Long-term potentiation in single wide dynamic range neurons induced by noxious stimulation in intact and spinalized rats. Prog Brain Res 129:153-161. CrossRef Medline

Swank RL, Watson CW (1949) Effects of barbiturates and ether on spontaneous electrical activity of dog brain. J Neurophysiol 12:137-160. Medline

Taepavarapruk N, McErlane SA, Soja PJ (2002) State-related inhibition by GABA and glycine of transmission in Clarke's column. J Neurosci 22: 5777-5788. Medline

Walton KD, Llinás RR (2010) Central pain as a thalamocortical dysrhythmia: a thalamic efference disconnection? In: Translational pain research: from mouse to man (Kruger L, Light AR, eds). Boca Raton, FL: CRC Press.

Weng HR, Lenz FA, Vierck C, Dougherty PM (2003) Physiological changes in primate somatosensory thalamus induced by deafferentation are de- 
pendent on the spinal funiculi that are sectioned and time following injury. Neuroscience 116:1149-1160. CrossRef Medline

Yeterian EH, Pandya DN (1985) Corticothalamic connections of the posterior parietal cortex in the rhesus monkey. J Comp Neurol 237:408-426. CrossRef Medline
Yeterian EH, Pandya DN (1994) Laminar origin of striatal and thalamic projections of the prefrontal cortex in rhesus monkeys. Exp Brain Res 99:383-398. Medline 